\title{
Discharge of Conidia of Entomophthora thaxteriana Petch from the Pea Aphid Acyrthosiphon pisum Harris
}

\author{
By N. WILDING \\ Rothamsted Experimental Station, Harpenden, Hertfordshire
}

(Accepted for publication 28 September 197I)

\begin{abstract}
SUMMARY
At $2 \mathrm{I}^{\circ}$, conidia of Entomophthora thaxteriana were first discharged from infected pea aphids about 6 to $9 \mathrm{~h}$. after the aphids died and the rate of discharge was highest during a short period about $9 \mathrm{~h}$. later. In constant light, the rate then decreased and discharge ended about $36 \mathrm{~h}$. after an infected aphid died; in constant darkness the maximum rate $\left(2 \times 10^{3}\right.$ conidia/h./aphid $)$ was only one-quarter of that in constant light but it was maintained for Io h. In alternating $\mathrm{I} 2 \mathrm{~h}$. light, $\mathrm{I} 2 \mathrm{~h}$. darkness, the rate of conidium discharge increased substantially $2 \mathrm{~h}$. after the admission of light and much decreased $2 \mathrm{~h}$. after light was excluded. In constant light, the average number of conidia discharged from one adult apterous aphid was at least $10^{5}$, twice that in constant darkness. Discharge of conidia began earliest at $20^{\circ}$ but the rate of discharge was highest at $25^{\circ}$. Ultimately, similar numbers of conidia were discharged at any temperature from 5 to $25^{\circ}$; conidia were not discharged at o or $30^{\circ}$.
\end{abstract}

INTRODUCTION

Several authors (Ali, 1957; Ege, 1965; Evlakhova \& Voronina, 1965; Callaghan, 1969) found that more conidia were discharged in light from cultures of Entomophthora species on artificial media, than in darkness, though Speare (1912) found that conidia of Entomophthora pseudococci Speare (= Entomophthora apiculata) were discharged mainly at night. Callaghan (1969) also found that, when a culture of Conidiobolus coronatus Srin. and Thirum. (= Entomophthora coronata) was transferred from dark to light, discharge increased and, in alternating $\mathrm{I} 2 \mathrm{~h}$. light, $12 \mathrm{~h}$. dark, a diurnal rhythm of discharge developed. Ali (1957) and Ege (1965) also found that the optimum temperature for discharge of conidia of Entomophthora species on artificial media was about $20^{\circ}$. Similarly, Hamilton (1959) found most Entomophthora conidia in the air at about $20^{\circ}$.

The effect of light and temperature on the discharge of conidia of Entomophthora species from their natural hosts has not been reported. Observations on this were made for Entomophthora thaxteriana Petch on pea aphids, Acyrthosiphon pisum Harris.

\section{METHODS}

Source of infected aphids. Pea aphids, Acyrthosiphon pisum Harris infected with Entomophthora thaxteriana Petch were obtained originally from field samples of pea aphids on lucerne at Rothamsted during the autumn of 1967 . The fungus was maintained in the laboratory by infecting healthy aphids with conidia discharged from infected ones. Aphids died 2 to 4 days after infection. Those which had been dead for less than an hour and had been in the light for several hours before death were chosen for the experiments.

Apparatus. The approximate number of conidia produced per hour from individual 


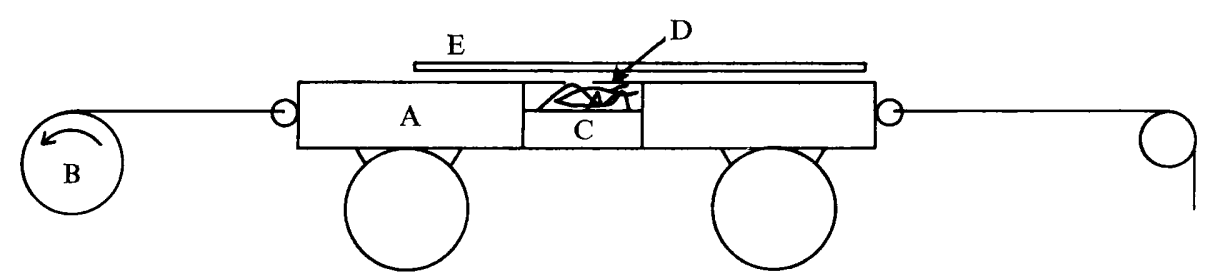

Fig. I. Apparatus for estimating the rate of conidia discharge. (For explanation, see text.)

aphids was found by means of a spore train similar to that used by Ingold \& Cox (1955) and Ingold \& Dring (1957) to measure the periodicity of spore discharge of Daldinia and Sordaria.

The spore train (Fig. I) consisted of a trolley (A) attached by a thread to a brass cylinder (B) $48 \mathrm{~mm}$. in circumference, turned by a spring-driven 24 -h. clock. The rotation of the cylinder drew the trolley along a rail uniformly at $2 \mathrm{~mm}$./h.; minor fluctuations were avoided by tensioning a thread attached to the rear of the trolley.

Conidia discharged from each of three aphids were trapped simultaneously. The aphids were placed on damp wadding (C) $30 \mathrm{~mm}$. apart in a row at right angles to the line of movement on a piece of thin perspex attached to the trolley. Discharged conidia passed through a $2 \mathrm{~mm}$. slit in a piece of celluloid (D) secured to the trolley immediately above the aphids, and adhered to a removable perspex plate, (E), fixed I $\mathrm{mm}$. above the celluloid. The plate was not coated with a sticky medium because the conidia were naturally adherent. Tests showed that most conidia, even in the dark, were cast upwards. However, some of them, especially those directed at an acute angle to the slide, fell short. Consequently counts of conidia in sample areas of the plate underestimated the total number of conidia per aphid.

The whole apparatus, apart from the clock, pulley and weight, was on a perforated shelf in a perspex tank containing water. This provided a humidity sufficient to avoid desiccation of the conidia while preventing their germination.

For the start of each experiment, the trolley was arranged so that the centre of the slit in the celluloid which covered the three aphids was $6 \mathrm{~mm}$. from the right-hand end (Fig. I) of the perspex plate. Three rectangular conidial deposits, each about $48 \mathrm{~mm}$. long, were thus obtained on each plate. After $24 \mathrm{~h}$. the plate was replaced with another, and the trolley returned to its starting position.

For tests on the effect of light on conidium discharge, conidia seen in the area of the field of view through an eyepiece graticule $\left(0.569 \mathrm{~mm} .^{2}\right.$ at a magnification of $\left.\times 100\right)$ were counted in 13 areas, $2 \mathrm{~mm}$. apart along lines (time-zones) at right angles to the longitudinal axis of each conidial deposit. This was repeated at $2 \mathrm{~mm}$. (representing $\mathrm{I} h$.) intervals along each deposit and the total number of conidia produced per aphid per hour was calculated from each line of counts. Had the deposition of conidia not been restricted by the slit, and had the aphids been stationary, a circular deposit with a diameter equal to the width of the band would have been obtained from each aphid. Most conidia would have been at the centre of the circle and fewest at the edge. Therefore, for each time-zone, parts of seven circles of diameter 2,6, I0, I4, I8, 22 and $26 \mathrm{~mm}$. were envisaged. The central, or 7 th, count lay in the central $2 \mathrm{~mm}$. diam. circle, the 6 th and 8 th counts in the ring immediately surrounding it and extending to $6 \mathrm{~mm}$. diam. The total numbers of conidia that would have been deposited in the central circle and successive rings were calculated from the areas of the rings relative to 


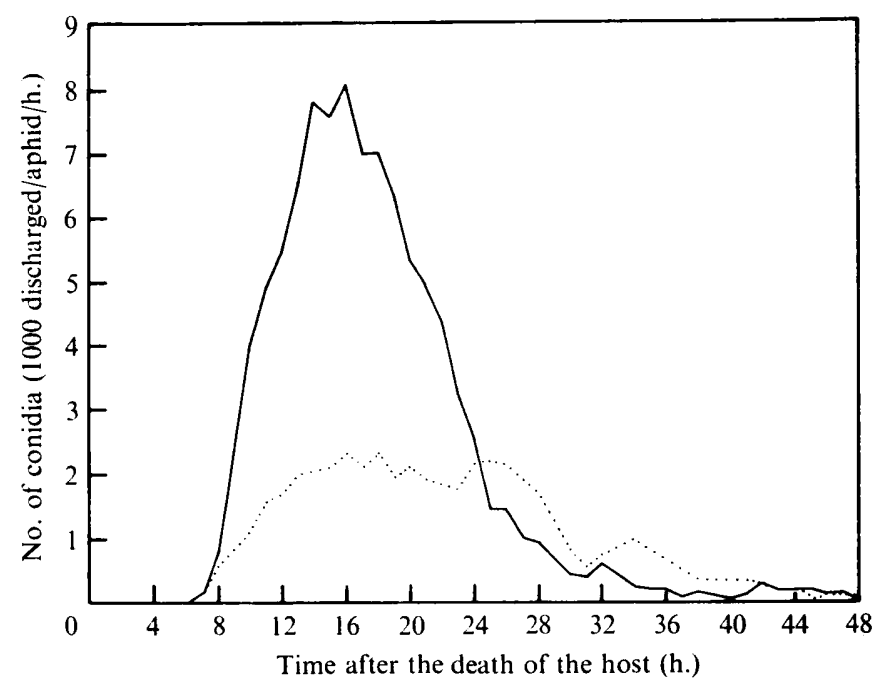

Fig. 2. The discharge of conidia of Entomophthora thaxteriana from Acyrthosiphon pisum at $2 \mathrm{I}^{\circ}$ in the light (solid line) and dark (dotted line).

that of the areas sampled. The sum of these totals was the total number of conidia produced in $\mathrm{I} \mathrm{h}$. A few conidia were cast up to $4 \mathrm{~mm}$. beyond each end of the $48 \mathrm{~mm}$. rectangle, so two extra bands of counts were made before the starting position and two more after the end position, on each plate. The first five bands of the second and subsequent plates were then added to the last five bands of the immediately preceding plate. This was equivalent to placing the starting positions of each plate on the finishing position of the one before. Thus an unbroken series of counts, each corresponding to an hour, was obtained.

For tests on the effect of temperature on conidium discharge, conidia were counted in short traverses (Hirst, 1953), $200 \mu \mathrm{m}$. wide, of each deposit on the plate at $2 \mathrm{~mm}$. intervals. Total numbers could not be assessed by this method. Only relative numbers of conidia produced per aphid per hour were obtained. As before, conidia in four extra traverses were counted to allow for scatter beyond the starting and ending zones of each $48 \mathrm{~mm}$. deposit and added to those in corresponding traverses on previous and subsequent plates.

Light and temperature conditions. The effect of light on conidium discharge was tested at $21^{\circ}$. Light, when provided, was supplied by four $20 \mathrm{~W}$ fluorescent strip-lights giving an intensity of $1250^{\prime}$ lux at the surface of the aphids. Conidium discharge was examined in continuous light, continuous darkness and in alternating periods of $12 \mathrm{~h}$. light, $12 \mathrm{~h}$. dark.

The effect of temperature was measured in continuous light supplied by two $20 \mathrm{~W}$ fluorescent strip lights giving an intensity of 460 lux at the aphids' surfaces.

\section{RESULTS}

Fig. 2 compares the average rate of conidium discharge obtained from six infected aphids in continuous light with that from six in continuous darkness. In light and dark, conidia were first discharged 6 to $9 \mathrm{~h}$. after the aphids died and were discharged at the highest rate about $9 \mathrm{~h}$. later. The maximum rate in constant light $\left(8 \times \mathrm{IO}^{3} / \mathrm{h}\right.$. $)$ was four times that in the dark but in the dark it was maintained for about so h., whereas in light it soon 

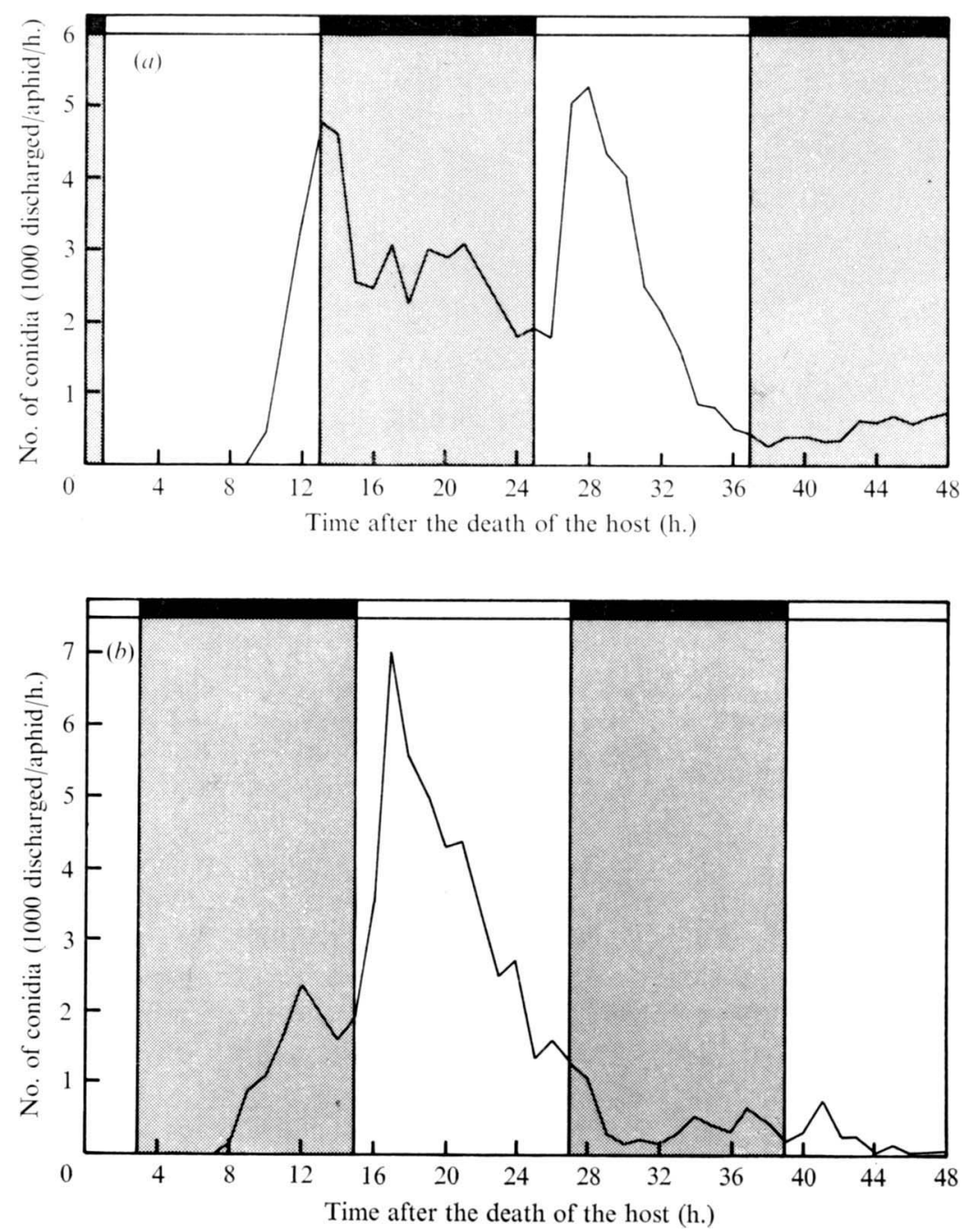

Fig. $3(a, b)$. The discharge of conidia of Entomophthora thaxteriana from Acyrthosiphon pisum at $2 \mathrm{I}^{\circ}$ in alternating light and dark.

slowed after reaching the maximum. The average total number of conidia produced per aphid in continuous light was at least $9.9 \times 10^{4}$ and in continuous darkness at least $4.9 \times 10^{4}$.

Fig. $3(a)$ and $(b)$ each show the average rate of conidium discharge obtained from three aphids in alternating $\mathrm{I} 2 \mathrm{~h}$. light, $\mathrm{I} 2 \mathrm{~h}$. dark. In the first test (Fig. 3a), light was first admitted $\mathrm{I} h$. after the aphids died. The average total number of conidia per aphid was $8.4 \times 10^{4}$. In the second test (Fig. $3 b$ ) light was first excluded $3 \mathrm{~h}$. after the host's death. The average total number of conidia per aphid was $6 \cdot \mathrm{I} \times 10^{4}$. In alternating $12 \mathrm{~h}$. light, $\mathrm{I} 2 \mathrm{~h}$. dark, the rate of discharge increased $2 \mathrm{~h}$. after the admission of light, to twice that immediately before light was admitted. Similarly, the rate decreased, $2 \mathrm{~h}$. after the exclusion of light, to half that immediately before. The total number of conidia discharged per aphid was intermediate between that in the dark and light. 


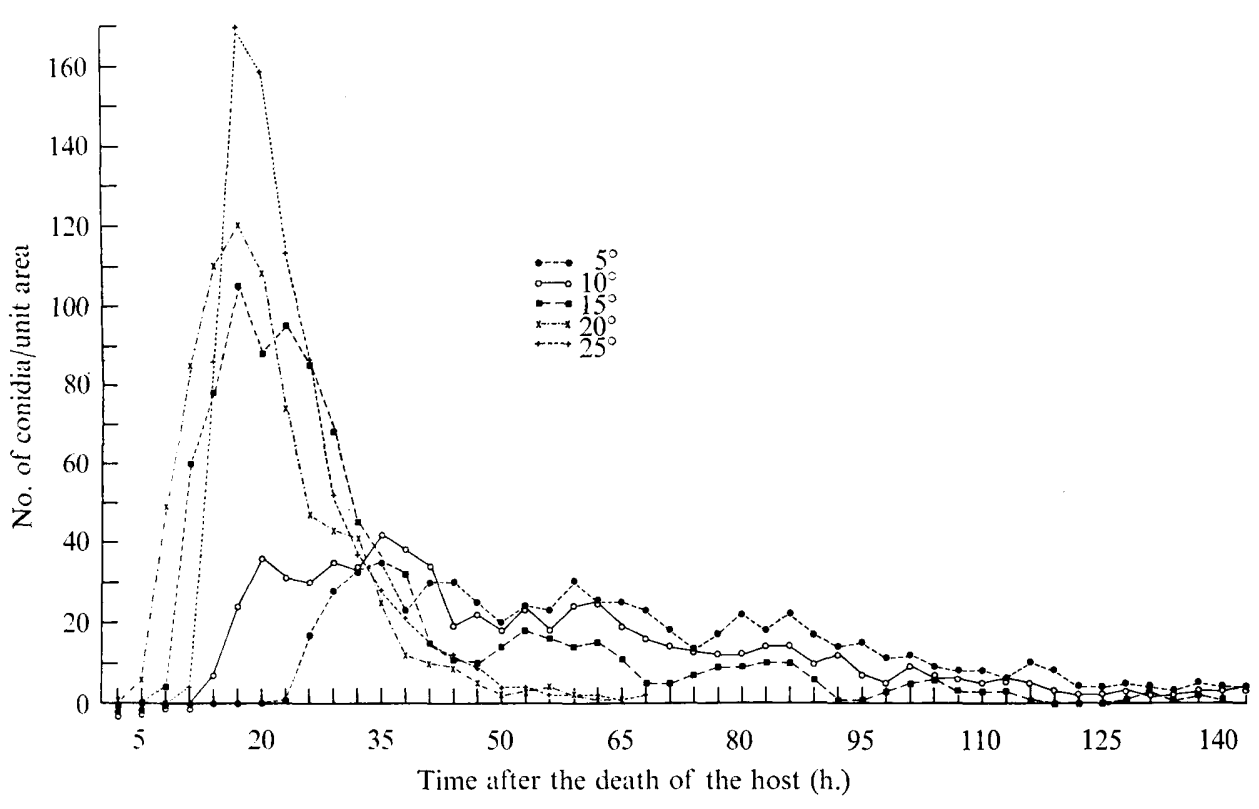

Fig. 4. The discharge of conidia of Entomophthora thaxteriana from Acyrthosiphon pisum in the light at temperatures from 5 to $25^{\circ}$. The points plotted are the means of counts at each of $3 \mathrm{~h}$.

Fig. 4. compares the mean rate of conidium discharge from three aphids at 5 , Io and $15^{\circ}$ and from six aphids at 20 and $25^{\circ}$ in continuous light. Conidia were not discharged at $0^{\circ}$ in the light or at $30^{\circ}$ in light or dark. Discharge started earliest, $5 \mathrm{~h}$. after the host's death, at $20^{\circ}$, but at $25^{\circ}$ the maximum discharge rate was $\mathrm{I} \cdot 4 \times$ that at $20^{\circ}$ and at both temperatures, the maximum rate was attained $17 \mathrm{~h}$. after the host's death. Ultimately approximately the same numbers of conidia were discharged from a single aphid at all temperatures; the mean numbers of conidia per unit area at 5, Io, 15, 20 and $25^{\circ}$ were in the proportions $0.9 \mathrm{I}: 0.90: \mathrm{I} \cdot 2 \mathrm{I}: \mathrm{I} \cdot 00: \mathrm{I} \cdot 07$, with no significant differences except between the numbers at $5^{\circ}$ and $15^{\circ}(P<0.05)$ and those at $10^{\circ}$ and $15^{\circ}(P<0.05)$.

The large difference between the rates of conidium discharge in light and dark (Fig. 2, $3 a$ and $b$ ) at $2 \mathrm{I}^{\circ}$ was probably caused by light energy and not radiant heat from the fluorescent lights, because the difference in the rate of discharge in the light at 20 and $25^{\circ}$ was small (Fig. 4) compared with the difference between discharge in light and dark at $21^{\circ}$ (Fig. 2). Also there was no discharge, even in the dark, at $30^{\circ}$, so at least radiation could not have caused a rise to that temperature.

\section{DISCUSSION}

Light enhanced the rate of conidium discharge of Entomophthora thaxteriana from its natural host and the optimum temperature for discharge was $20^{\circ}$ to $25^{\circ}$. These results are similar to those of Ali (1957), Ege (1965), Evlakhova \& Voronina (1965) and Callaghan (1969), on the conidium discharge of Entomophthora species in culture. The increased rate of conidium discharge from cultures of Conidiobolus coronatus, subjected to alternating periods of I $2 \mathrm{~h}$. light, I $2 \mathrm{~h}$. dark, was also found by Callaghan (I969) to be approximately five times that in the dark shortly after each admission of light. The twofold increase in 
E. thaxteriana suggests that there are large differences between species in the degree of their response to light.

The only previous record of the number of conidia produced by a species of Entomophthora on its host is that of Gilbert \& Kuntz (1926) who estimated that E. fresenii Nowakowski produced a total of between 400 and 1000 conidia on a single Aphis spiraecola Patch. In the present investigation Entomophthora thaxteriana discharged at least 50,000 to 100,000 conidia from Acyrthosiphon pisum and even though A. pisum is a larger aphid than Aphis spiraecola, it would not be expected to support the development of 100 times the number of conidia.

The results for Entomophthora thaxteriana resemble those of Yendol \& Paschke (1967) where conidia of Entomophthora sphaerosperma Fresenius were first discharged $6 \mathrm{~h}$. after the death of infected geometrid larvae. Similarly, Brefeld, according to Goldstein (1923), found that Entomophthora muscae Cohn on houseflies discharged conidia for 2 days; however, these authors did not give the temperature at which their observations were made.

The results presented here are important in the epizootiology of disease caused by Entomophthora thaxteriana in populations of aphids in the field. It was previously found (Wilding, 1969) that conidia of E. thaxteriana were discharged from infected Acyrthosiphon pisum only when the relative humidity exceeded $90 \%$, and that most conidia were discharged when the host was on a damp substrate. Thus, from the present results, the air in the microenvironment of the host must consistently exceed $90 \% \mathrm{RH}$, at $2 \mathrm{I}^{\circ}$, for at least $6 \mathrm{~h}$. after the death of the host before any conidia are discharged, and for $17 \mathrm{~h}$. before the rate of discharge is highest.

I thank Caroline B. Tyson and A. J. Wiseman for their assistance in this work.

\section{REFERENCES}

AlI, S. B. (1957). A Mycological Study of a Species of Entomophthora Attacking Aphids. Ph.D. Thesis, University of London.

Callaghan, A. A. (1969). Light and spore discharge in Entomophthorales. Transactions of the British Mycological Society 53, 87-97.

EGE, O. (1965). Ein Beitrag zur Biologie einiger aphidivorer Entomophthoraceen. Archiv für Mikrobiologie $52,20-48$.

Evlakhova, A. A. \& Voronina, E. (1965). Study on the Entomophthorosis of Aphididae for their practical application. Proceedings of XIII International Congress of Entomology, London, 1964, p. 75I .

Gilbert, E. M. \& Kuntz, W. A. (1926). Some diseases of Aphis spiraecola Patch. Quarterly Bulletin of the Florida State Plant Board 1o, I-6.

Goldstein, B. (1923). Resting spores of Empusa muscae. Bulletin of the Torrey Botanical Club 50, 3I 7-327.

Hamilton, E. D. (1959). Studies on the air-spora. Acta Allergologica 13, 143-175.

Hirst, J. M. ( I953). Changes in atmospheric spore content: diurnal periodicity and the effects of weather. Transactions of the British Mycological Society 36, 375-393.

INGOLD, C. T. \& Cox, V. J. (1955). Periodicity of spore discharge in Daldinia. Annals of Botany 19, $20 \mathrm{I}-209$.

Ingold, C. T. \& Dring, V. J. (1957). An analysis of spore discharge in Sordaria. Annals of Botany 21, $465-477$.

SPEARE, A. T. (I9I2). Fungi parasitic upon insects injurious to sugar cane. (Report. Hawaiian Sugar Planters' Association Experiment Station.) Pathology and Physiology Serial Bulletin 12, I-62.

Wilding, N. (1969). Effect of humidity on the sporulation of Entomophthora aphidis and E. thaxteriana. Transactions of the British Mycological Society 53, I 26-1 30.

YeNDOL, W. G. \& PASCHKE, J. D. (I967). Infection of a looper complex by Entomophthora sphaerosperma Fresenius. Journal of Invertebrate Pathology 9, 274-276. 